\title{
PROTOTYPE PENGONTROLAN SISTEM HIDROLIK PADA GUDANG BERBASIS ARDUINO
}

\author{
Ilamsyah $^{1}$ \\ Feizal Hazriel Maulana ${ }^{2}$ \\ Roy Denni Simanjuntak \\ Dosen STMIK Raharja Tangerang ${ }^{1,}$ Mahasiswa STMIK Raharja Tangerang ${ }^{2,3}$ \\ J1.Jendral Sudirman No.40, Modernland, Tangerang ${ }^{1,2,3}$ \\ Email : ilamsyah@raharja.info ${ }^{1}$, feizal.hazriel@ raharja.info ${ }^{2}$, roy.denni@ raharja.info ${ }^{3}$
}

\begin{abstract}
ABSTRAK
Seiring dengan berkembangnya dunia teknologi mengenai pengontrolan otomatis pada zaman sekarang ini, membuat sistem pengontrolan secara otomatis sangat membantu seseorang dalam meringankan pekerjaannya. Banyak diluar sana yang sudah menggunakan berbagai macam sistem kerja otomatis. Sistem pengontrolan secara otomatis sekarang ini bisa dibuat berbagai macam ragamnya seperti pengontrolan sistem hidrolik secara otomatis untuk menghindari terjadinya banjir. Pengontrolan ini dilakukan menggunakan sebuah mikrokontroler Arduino dan sensor Ultrasonik, dimana mikrokontroler sebagai media input program yang akan di proses dan sensor Ultrasonik untuk mengukur jarak ketinggian air. Metode yang digunakan untuk merancang sistem hidrolik ini menggunakan flowchart, Perangkat keras yang akan digunakan meliputi Arduino Uno, Sensor Ultrasonik, Motor penggerak (DC), Lampu LED, Buzzer dan beberapa alat elektronika lainnya. Perancangan perangkat kerasnya menggunakan Arduino Uno sebagai media untuk menanamkan program dan perancangan perangkat lunak dilakukan dengan menggunakan program Ide Arduino. Pengontrolan otomatis ini bertujuan untuk menghindari kerusakan pada barang yang diakibatkan oleh banjir.
\end{abstract}

Kata Kunci : Pengontrolan otomatis, Mikrokontroler, Sensor

\section{ABSTRACT}

Along with the development of the automatic control the world of technology at this present time, making the control system automatically helps a person to ease his work. A lot out there who already using a wide variety of automatically working systems. Automatic control system now can make various kinds of variety such as controlling hydraulic system automatically to avoid flooding. This control is done using an Arduino microcontroller and ultrasonic sensors, which the microcontroller as input media program that will be in the process and ultrasonic sensors to measure the distance of the water level. The method used to design the hydraulic system uses a flowchart, The hardware used includes Arduino Uno, Ultrasonic Sensors, Motor-drive (DC), Lamp LED, buzzer and several other electronic devices. The design of the hardware using the Arduino Uno as a medium to instill the program and software design were performed using of Arduino. Automatic control is intended to avoid damage to the goods caused by flooding.

Keywords : Automatic control, Microcontroller, Sensor 


\section{PENDAHULUAN}

Perubahan cuaca di Indonesia sering terjadi, perubahannya pun sulit di prediksi. Kadang pada saat musim kemarau tiba-tiba bisa saja turun hujan deras. Derasnya hujan yang turun di Indonesia sering kali mengakibatkan banjir di beberapa wilayah, terutama di wilayah yang berada di dataran rendah, yang wilayah resapan airnya kurang. Apalagi disaat kondisi musim penghujan, banyak terjadi banjir dimana-mana. Banjir dapat terjadi dimana saja seperti di pemukiman warga, perkantoran, pabrik dan ditempat-tempat yang memiliki daya tampung atau resapan air yang kurang. Wilayah dataran yang rendah sering mengalami banjir jika ditimpa hujan yang lebat dan terus menerus, hal ini mengakibatkan kerugian materi yang cukup besar.

Pergudangan pabrik di Indonesia banyak sekali menyimpan barang-barang berharga milik perusahaan. Tidak hanya barang berharga, tetapi juga menyimpan barang-barang yang siap untuk di distribusikan ke berbagai wilayah di Indonesia yang harus dijaga kondisi dan keamanan tempat penyimpanannya. Keamanan yang dimaksud tidak hanya aman dari pencurian, tetapi juga harus aman dari bencana alam seperti banjir. Hal ini membuat para operator gudang untuk dapat menempatkan barang-barang tersebut secara aman. Untuk gudang yang berada di dataran tinggi memang tidak perlu khawatir bila terjadi hujan lebat yang biasanya disertai banjir. Lain halnya dengan gudang yang berada di wilayah dataran rendah, karena bila turun hujan sewaktu-waktu bisa terjadi banjir yang tidak diinginkan.

Dengan adanya permasalahan tersebut, maka penulis mengambil judul penelitian "PROTOTYPE PENGONTROLAN SISTEM HIDROLIK PADA GUDANG BERBASIS ARDUINO". Dengan harapan barang-barang yang tersimpan di gudang akan aman dari bahaya banjir. Ini merupakan alat keamanan yang terdiri dari sebuah sistem hidrolik dan mikrokontroller Arduino yang di dukung dengan alat-alat elektronik lainnya. Alat ini dibuat untuk mencegah terjadinya kerusakan pada barang digudang yang diakibatkan karena terendam air banjir. Dengan adanya alat ini, diharapkan operator gudang tidak perlu khawatir dengan keadaan barang digudang karena secara otomatis sistem hidrolik akan menaikkan barang jika ketinggian air sudah mendekati batas tertentu, hal ini akan dapat menghindarkan barang dari kerusakan.

\section{PERMASALAHAN}

Dalam pembuatan alat ini ditemukan beberapa masalah yang meliputi:

1. Bagaimana cara mengontrol sistem hidrolik menggunakan mikrokontroler Arduino?

2. Bagaimana cara kerja dari sistem hidrolik untuk mengamankan barang-barang tersebut?

3. Bagaimana kemampuan alat ini dalam mengamankan barang-barang di gudang?

\section{LANDASAN TEORI}

\section{Definisi Sistem Hidrolik}

Sistem hidrolik merupakan suatu bentuk perubahan atau pemindahan daya dengan menggunakan media penghantar berupa fluida cair untuk memperoleh daya yang lebih besar dari daya awal yang dikeluarkan. Dimana fluida penghantar ini dinaikkan tekanannya oleh pompa pembangkit tekanan yang kemudian diteruskan ke silinder kerja melalui pipa-pipa saluran dan katup-katup. Gerakan translasi batang piston dari silinder kerja yang diakibatkan oleh tekanan fluida pada ruang silinder dimanfaatkan untuk gerak maju dan mundur. 


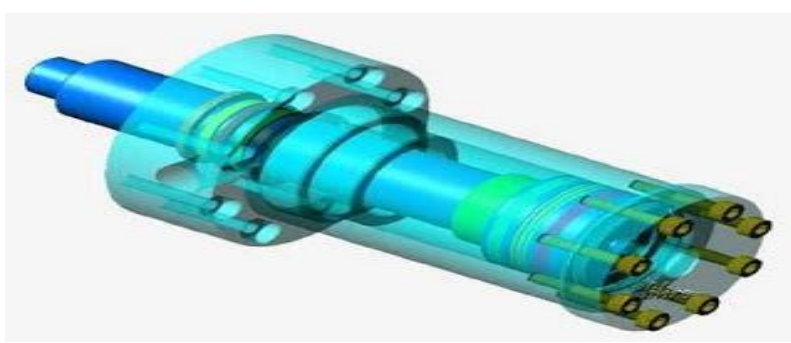

Gambar 1. Pompa Hidrolik

\section{Defenisi Arduino Uno}

Arduino Uno adalah sebuah board mikrokontroler berbasis ATmega328. Arduino Uno memiliki 14 pin digital input / output (6 di antaranya dapat digunakan sebagai output PWM), 6 input analog, sebuah osilator Kristal $16 \mathrm{MHz}$, sebuah koneksi USB, sebuah power jack, sebuah ICSP header, dan sebuah tombol reset. Arduino Uno memuat semua yang dibutuhkan untuk menunjang mikrokontroler, mudah menghubungkannya ke sebuah komputer dengan sebuah kabel USB atau mensuplainya dengan sebuah adaptor AC ke DC atau menggunakan baterai untuk memulainya.

Arduino Uno berbeda dari semua board Arduino sebelumnya, Arduino Uno tidak menggunakan chip driver FTDI USB-to-serial. Sebaliknya, fitur-fitur Atmega16U2 (Atmega8U2 sampai ke versi R2) diprogram sebagai sebuah pengubah USB ke serial. Revisi 2 dari board Arduino Uno mempunyai sebuah resistor yang menarik garis 8U2 HWB ke ground, yang membuatnya lebih mudah untuk diletakkan ke dalam DFU mode

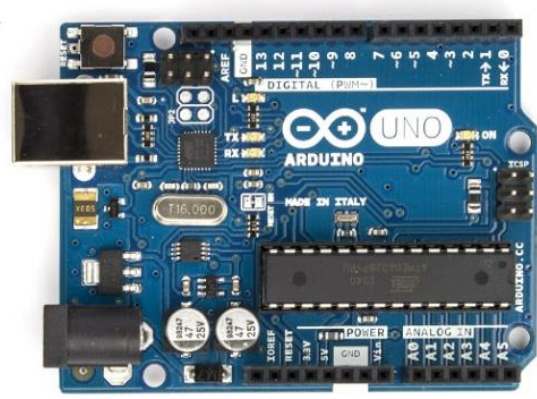

Gambar 2. Arduino Uno

1. Spesifikasi Arduino Uno

Berikut adalah spesifikasi dari mikrokontroler Arduino Uno (ATmega328) :

a. Mikrokontroler ATmega328.

b. Catu Daya 5V.

c. Tegangan Input rekomendasi 7-12 V.

d. Tegangan Input batasan 6-20 V.

e. Pin I/O Digital berjumlah 14.

f. Pin input analog berjumlah 6 .

g. Arus DC per Pin I/O $40 \mathrm{~mA}$.

h. Arus DC per Pin I/O untuk pin $3.3 \mathrm{~V} 50 \mathrm{~mA}$

i. Flash memori $32 \mathrm{~KB}$ ( Atmega 328 ), dimana 0.5 digunakan oleh bootloader.

j. SRAM $2 \mathrm{~KB}$. 
k. EEPROM $1 \mathrm{~KB}$.

1. Clock Speed $16 \mathrm{MHz}$.

\begin{tabular}{|c|c|}
\hline Mikrokontroler & ATmega328 \\
\hline Tegangan pengoperasian & $5 \mathrm{~V}$ \\
\hline $\begin{array}{c}\text { Tegangan input yang } \\
\text { disarankan }\end{array}$ & $7-12 \mathrm{~V}$ \\
\hline Batas tegangan input & $6-20 \mathrm{~V}$ \\
\hline Jumlah pin I/O digital & 14 (6 di antaranya menyediakan keluaran PWM) \\
\hline Jumlah pin input analog & 6 \\
\hline Arus DC tiap pin $\mathrm{I} / \mathrm{O}$ & $40 \mathrm{~mA}$ \\
\hline Arus DC untuk pin $3.3 \mathrm{~V}$ & $50 \mathrm{~mA}$ \\
\hline Memori Flash & $\begin{array}{c}32 \mathrm{~KB} \text { (ATmega328), sekitar } 0.5 \mathrm{~KB} \text { digunakan oleh } \\
\text { bootloader }\end{array}$ \\
\hline SRAM & $2 \mathrm{~KB}$ (ATmega328) \\
\hline EEPROM & $1 \mathrm{~KB}$ (ATmega328) \\
\hline Clock Speed & $16 \mathrm{MHz}$ \\
\hline
\end{tabular}

Tabel 1. Spesifikasi Arduino Uno

\section{Literature Review}

1. Penelitian yang dilakukan oleh Muhammad Khiabani Fakhri dari STMIK Raharja yang berjudul "PENGUKUR TINGGI BADAN MENGGUNAKAN SENSOR ULTRASONIK BERBASIS MIKROKONTROLER ATMEGA328 DUAL MODE" pada tahun 2015. Penelitian ini membahas tentang mengukur ketinggian dengan menggunakan sensor ultrasonik.

2. Penelitian Skripsi oleh Ilfan Arifin dari Universitas Negeri Semarang yang berjudul "AUTOMATIC WATER LEVEL CONTROL BERBASIS MIKROCONTROLLER DENGAN SENSOR ULTRASONIK" pada tahun 2015. Penelitian ini membahas tentang memompa air secara otomatis dengan mengukur ketinggian air menggunakan sensor ultrasonik.

3. Penelitian yang dilakukan oleh Budi Susilo dari Universitas Diponegoro yang berjudul "RANCANG BANGUN SIMULATOR PNEUMATIK SEBAGAI ALAT PEMINDAH BARANG" pada tahun 2013. Penelitian ini membahas tentang membuat alat simulator tentang cara kerja sistem otomasi pneumatik secara sederhana.

4. Penelitian yang dilakukan oleh Nurul Uswah Azizah dari Universitas Islam Negeri Syarif Hidayatullah Jakarta yang berjudul "RANCANG BANGUN PROTOTIPE ALAT DETEKSI JARAK DENGAN SENSOR PING PADA MOBIL PENGANGKUT BARANG BERBASIS ARDUINO" pada tahun 2014. Penelitian ini membahas tentang pengontrolan mobil pengangkut barang menggunakan sensor ultrasonik.

5. Penelitian yang dilakukan oleh Ridwan Jakaria dari STMIK Raharja yang berjudul " PROTOTYPE PENGONTROLAN VOLUME AIR OTOMATIS DENGAN ARDUINO UNO PADA PDAM TIRTA BENTENG KOTA TANGERANG" Penelitian ini membahas 
tentang bagaimana sebuah sistem mikrokontroler yang dibuat dapat bekerja mengontrol level air didalam tandon dengan sensor jarak infrared.

\section{PEMECAHAN MASALAH}

I. Konsep Perancangan

Melakukan perancangan yang meliputi perangkat keras (hardware) dan perangkat lunak (software). Perangkat keras yang akan digunakan meliputi Arduino Uno, Sensor Ultrasonik, Motor penggerak (DC), Lampu LED, Buzzer dan beberapa alat elektronika lainnya. Perancangan perangkat kerasnya menggunakan Arduino Uno sebagai media untuk menanamkan program dan perancangan perangkat lunak dilakukan dengan menggunakan program Ide Arduino.

II. Perancangan Perangkat Keras

Berikut merupakan alur dari diagram blok, yang dimana terdapat konfigurasi seluruh rangkaian yang digunakan. Prinsip dari kerja sistem yang dirancang adalah sensor Ultrasonik yang memberi input kepada mikrokontroler dengan mengukur jarak benda selanjutnya mikrokontroler akan memberikan output kepada LED, buzzer dan motor DC.

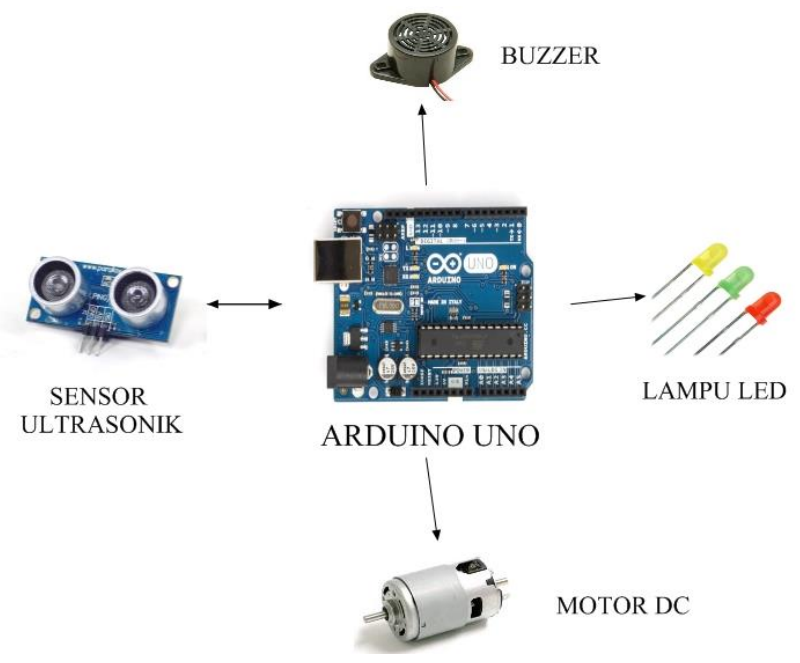

III. Merancang Schematik Hardware

Dalam pembuatan skematik menggunakan aplikasi Fritzing, yang merupakan aplikasi untuk merancang rangkaian elektronika yang sudah mendukung Arduino Library.

IV. Rangkaian Power Supply

Rangkaian catu daya yang digunakan mendapatkan sumber tegangan dari adaptor switching dengan output 12 volt. Tegangan tersebut kemudian diturunkan menjadi 5 volt tegangan DC, melalui IC regulator LM7805.

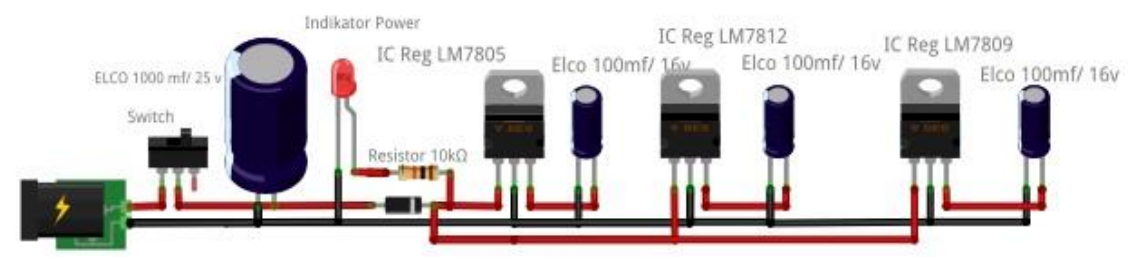

Gambar Rangkaian Power Supply 
V. Rangkaian Sensor Ultrasonik

Ultrasonik ini adalah Pemancar (transmitter) mengirimkan seberkas gelombang Ultrasonik, lalu diukur waktu yang dibutuhkan hingga datangnya pantulan dari obyek. Lamanya waktu ini sebanding dengan dua kali jarak sensor dengan obyek, sehingga didapat jarak sensor dengan obyek.

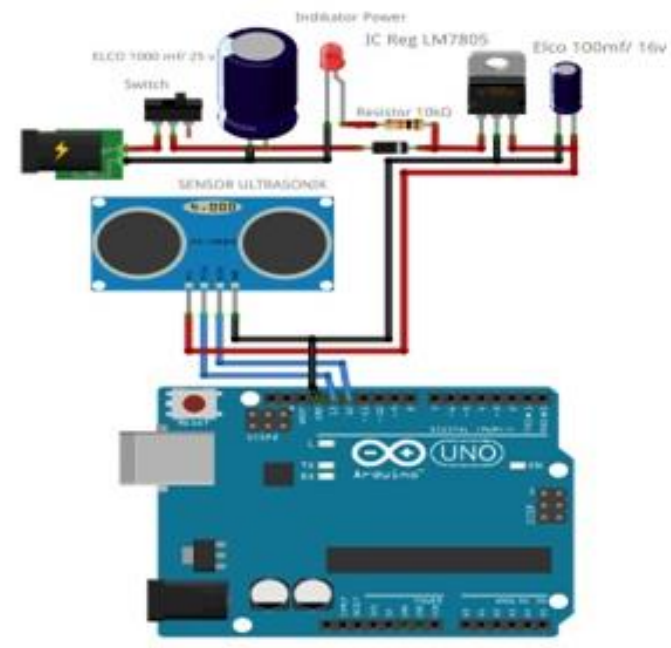

Gambar Rangkaian Sensor Ultrasonik

VI. Rangkaian Motor DC

Motor DC digunakan untuk penggerak sistem hidrolik agar dapat menaikkan barang. IC L293 adalah IC yang didesain khusus sebagai driver motor DC dan dapat dikendalikan dengan mikrokontroler.

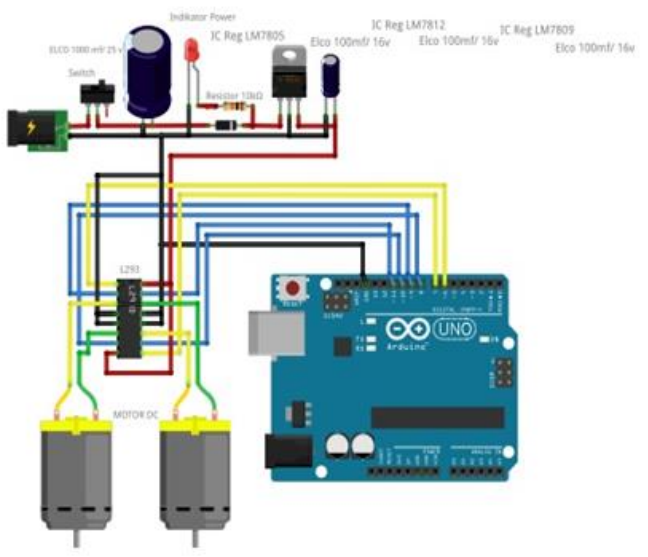

Gambar Rangkaian Motor DC

VII. Rangkaian Buzzer

Buzzer adalah sebuah komponen elektronika yang berfungsi untuk mengubah getaran listrik menjadi getaran suara. Pada dasarnya prinsip kerja Buzzer hampir sama dengan loud speaker, sama-sama bergetar dan menghasilkan suara. 


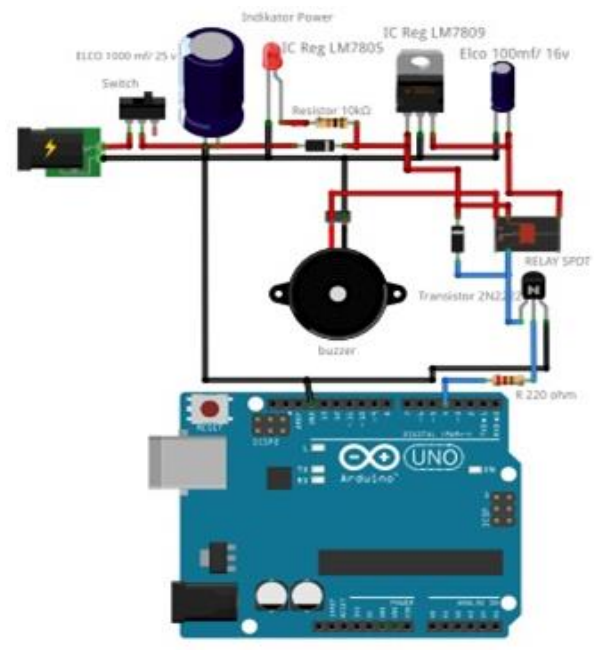

Gambar Rangkaian Buzzer

VIII. Rangkaian Lampu LED

Lampu LED digunakan sebagai lampu indikator pada sistem. Prinsip kerja dari rangkaian diatas adalah ketika pada saat mendapatkan input dari sensor Ultrasonik ketinggian air sudah tinggi maka lampu merah akan menyala. Sebaliknya jika ketinggian air rendah maka lampu hijau akan menyala.

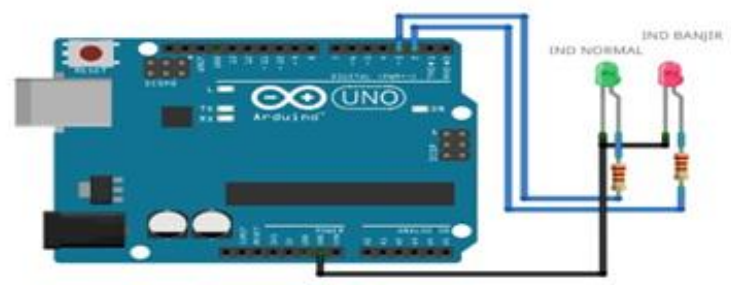

Gambar Rangkaian Lampu LED

IX. Rangkaian Sistem Secara Keseluruhan

Setelah melakukan perancangan perangkat keras dari seluruh komponen dan bahan yang digunakan, maka rangkaian sistem keseluruhan akan terlihat sebagai berikut:

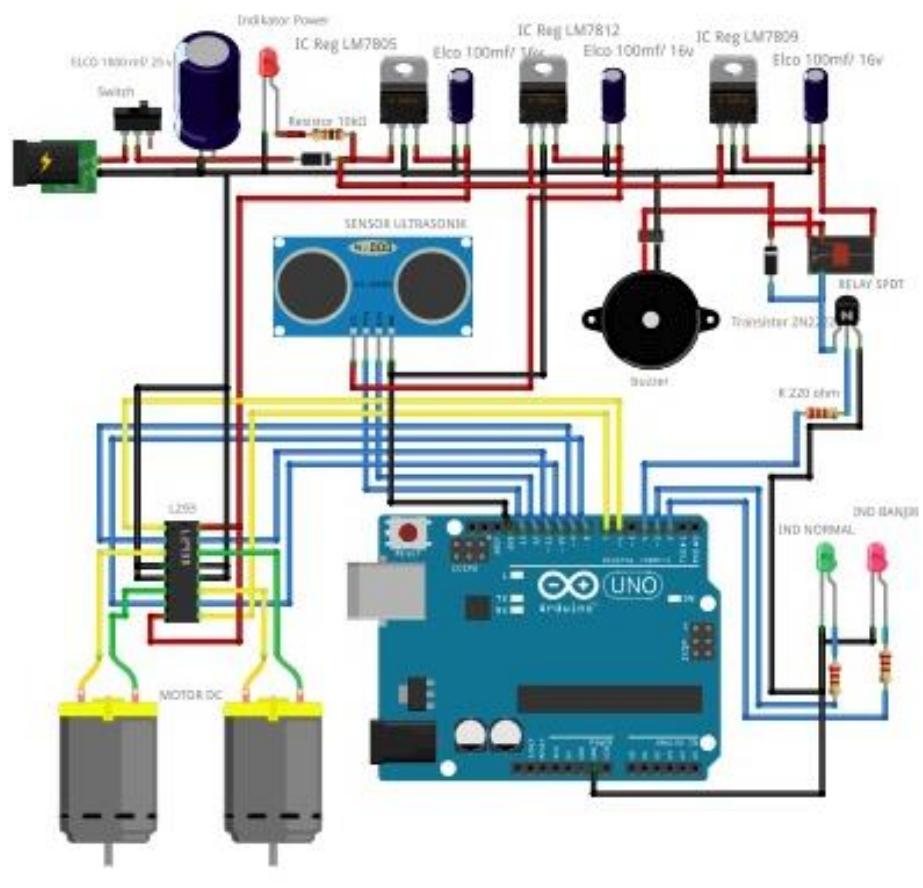

Gambar Rangkaian Secara Keseluruhan 
X. Flowchart

Pada pembuatan sebuah sistem kontrol diperlukan sebuah gambar yang dapat menjelaskan alur dan langkah-langkah dari cara kerja sebuah sistem yang dibuat, sehingga dapat memberikan penjelasan dalam bentuk gambar. Dari penelitian yang dilakukan menghasilkan flowchart sistem sebagai berikut:

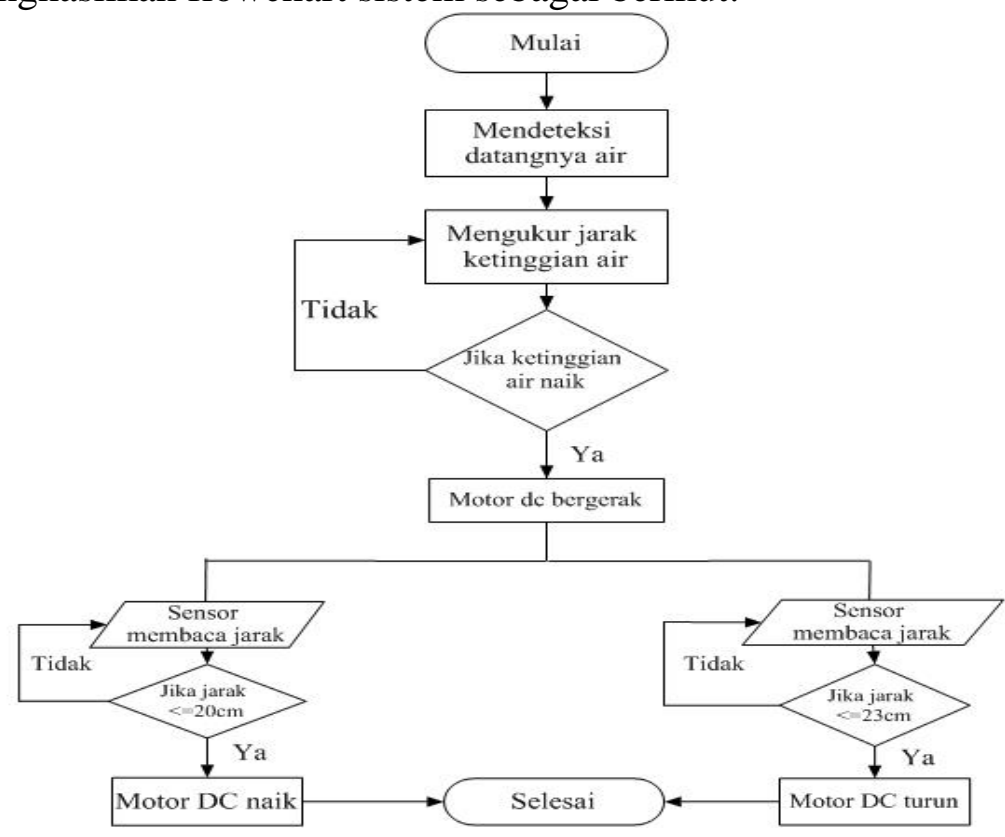

XI. Listing Program

Dalam pemrograman mikrokontroler Arduino yang akan dibuat, untuk menuliskan listing program secara keseluruhan dapat dilihat pada gambar berikut:
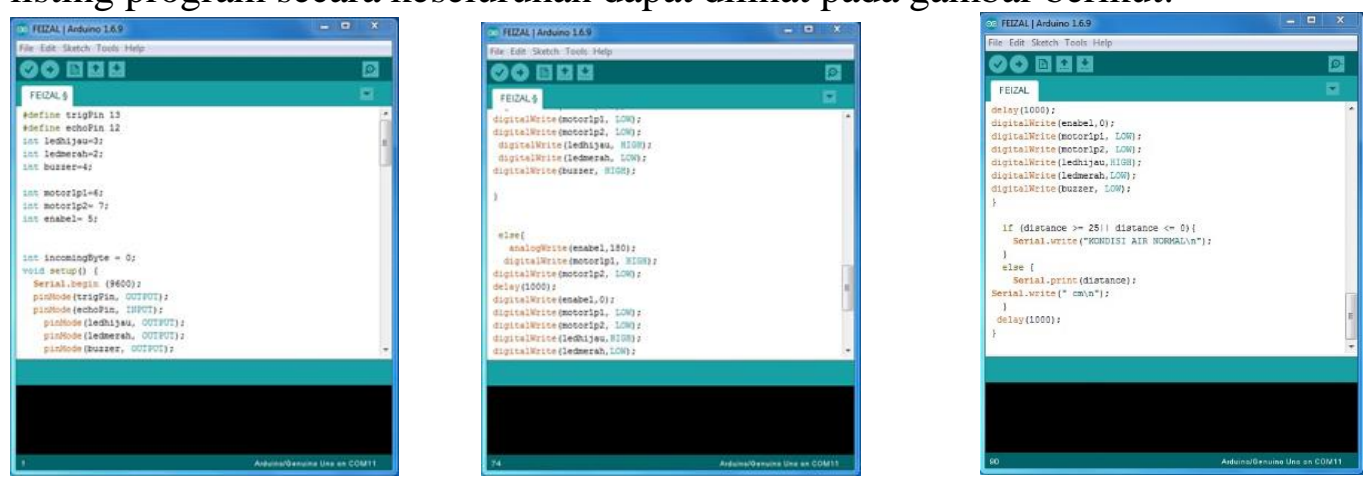

Gambar Listing Program Keseluruhan

\section{IMPEMENTASI}

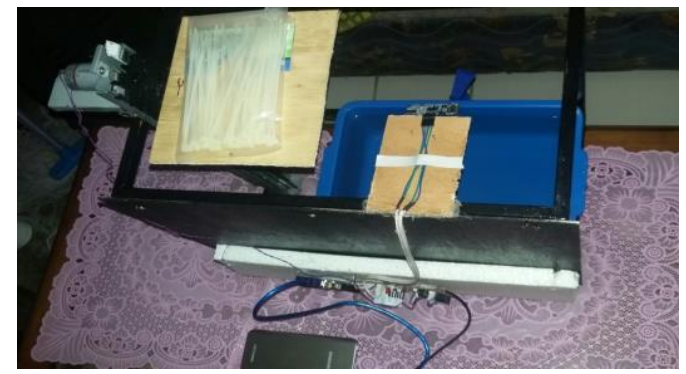

Gambar 3. Hasil alat dalam keadaan banjir 


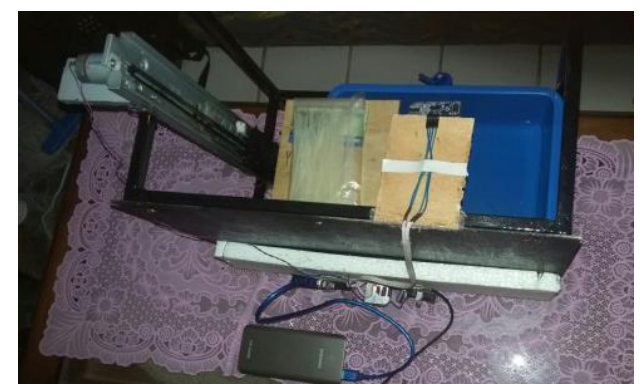

Gambar 4. Hasil alat dalam keadaan tidak banjir

\section{KESIMPULAN}

Berdasarkan analisa dari beberapa bab sebelumnya, dapat ditarik kesimpulan sebagai berikut

1. Cara mengontrol sistem hidrolik menggunakan mikrokontroler Arduino adalah dengan menggunakan program Arduino yang telah di coding kemudian rangkaian sistem hidrolik disambungkan dengan alat elektronika yang lain yang telah dihubungkan dengan mikrokontroler Arduino.

2. Cara kerja dari sistem hidrolik untuk mengamankan barang-barang dimana Sensor ultrasonik akan mendeteksi ketinggian air jika ketinggian air sudah maksimal seperti yang di codingkan pada program Arduino maka sistem hidrolik akan naik, sebaliknya jika ketinggian air minimum seperti yang di codingkan pada program Arduino maka sistem hidrolik akan turun.

3. Kemampuan sistem hidrolik menggunakan mikrokontroler Arduino dimana sistem ini dapat mengangkat beban sekitar 1-2 kg secara otomatis dengan pengaturan jarak menggunakan sensor ultrasonik dimana sensor akan membaca jarak ketinggian air.

\section{DAFTAR PUSTAKA}

[1] Apri Wahyudi (2012), "Trouble Shooting Mesin Hidrolik Pencetak Paving dengan Sistem Kontrol”. Universitas Negeri Semarang

[2] Budi Susilo (2013), "Rancang Bangunan Simulator Pneumatik sebagai Alat Pemindah Barang". Universitas Diponegoro

[3] Budiharto, Widodo. 2011. Aneka Proyek Mikrokontroler. Yogyakarta : Graha Ilmu.

[4] Faizal, Ahmad. 2012. Belajar Menggunakan Arduino. Yogyakarta : Graha Ilmu

[5] Muhammad Khiabani Fakhri (2015), "Pengukur Tinggi Badan Menggunakan Sensor Ultrasonik Berbasis Mikrokontroler Atmega328 Dual Mode”. STMIK Raharja

[6] Nurul Uswah Azizah (2014), "Rancang Bangun Prototype Alat Deteksi Jarak Dengan Sensor PING pada Mobil Pengangkut Barang Berbasis". Universitas Islam Negeri Syarif Hidayatullah Jakarta

[7] Pudyatmoko, Ary. 2013. Sistem Keamanan Kamar Kos Dengan Peringatan Alarm Dan Sms Berbasis Mikrokontroler Atmega32. Surakarta : Tugas Akhir, Universitas Muhammadiyah Surakarta.

[8] Purwanto, Sigit. Perancangan Sistem Pemanas Bearing Menggunakan Kontrol PI Berbasis Mikrokontroler ATMega 8535. Semarang: Universitas Diponegoro.

[9] Ridwan Jakaria, " Prototype Pengontrolan Volume Air Otomatis Dengan Arduino Uno pada PDAM Tirta Benteng Kota", STMIK Raharja 